\title{
MABUSE E MICHELE TOSINI: DIFERENTES ESTÉTICAS RELIGIOSAS*
}

\section{Fernanda Marinho}

Mestranda do Instituto de Filosofia e Ciências Humanas

História da Arte / UNICAMP

O presente trabalho se ocupará em estudar duas pinturas: uma holandesa, Madona com Menino e outra italiana Madona com Menino e São João Batista, conservadas hoje na Fundação Eva Klabin (FEK), pretendendo principalmente focalizar suas diferentes estéticas religiosas, mas também trazer à luz desta análise suas possibilidades autográficas.

A pintura holandesa aponta em sua ficha catalográfica o nome de Jan Gossaert (1478-1533), dito Mabuse, e a italiana o de Andrea d'Angolo (1503-1577), conhecido como Andréa del Sarto. No entanto, vale ressaltar e considerar em larga escala as novas pesquisas feitas por Luciano Migliaccio, autor do novo catálogo $A$ Coleção Eva Klabin, que sugere a possibilidade da holandesa ser de 1520 e aproxima a italiana a Michele di Rodolfo del Ghirlandaio, conhecido como Michele Tosini, datando-a de 1570.

As datações sugeridas contextualizam tais pinturas no período do Alto Renascimento europeu, fortemente marcado pelas inovações estéticas propostas por Rafael, Leonardo e Michelangelo. No entanto poderemos perceber suas diferentes tendências religiosas resultantes do fortalecimento do cisma luterano, consequentemente das manifestações reformistas dos Países Baixos, em contraposição à decadência do Humanismo face à Contra-Reforma que pretendia entre outros objetivos controlar com crescente severidade o trabalho artístico.

Pretende-se aqui analisar como estas diferenças religiosas se apresentam esteticamente nas obras em questão. Enquanto a Itália, sob o papado de Leão X, ainda estava em pleno desenvolvimento e propagação da forma renascentista, a Holanda, sob o governo do espanhol Carlos V, já via iniciar uma efervescência revoltosa do cisma luterano, que pretendia denunciar a vida desregrada, a opulência e o luxo do alto clero, a venda de cargos eclesiásticos, de relíquias sagradas e de indulgências, entre outros abusos da Igreja. Este, portanto, era o contexto histórico da pintura

\footnotetext{
* Trabalho de conclusão de graduação do curso de História da Arte da Universidade do Estado do Rio de Janeiro, com orientação de Maria Berbara.
} 
atribuída a Mabuse, ao passo que a atribuída a Tosini apresenta uma estética mais contra-reformista, de reação a esta crise papal.

Ambas representam a Virgem em companhia do Menino, evidenciando um momento de tranqüilidade e intimidade entre mãe e filho, na holandesa corroborado na ambientação escura da cena e na italiana na troca de olhares que focaliza a atenção da cena na afetividade materna.

Madona com Menino possui forte relação tanto com a tradição flamenga quanto com a italiana. A feição da Virgem nos remete a Gerard David e Lucas Van Leyden, enquanto que a figura musculosa do Menino e a sua posição relembram imediatamente Dürer, que absorveu muitas influências do Renascimento italiano.

Os artistas renascentistas dos Países Baixos ainda mantinham uma considerável afinidade com a estética gótica: formas humanas rígidas e alongadas e um especial destaque na contextualização espacial da cena, havendo assim grande investimento na representação das paisagens e na ornamentação do cenário. No entanto, traçando uma relação destas características com a pintura atribuída a Mabuse, podemos destacar nesta uma tendência à singularidade em certos aspectos. Há uma ênfase nítida na composição das formas humanas em detrimento da paisagística e da ornamentação. Seus personagens são inegavelmente o foco da cena, uma vez que o fundo escuro os destaca, tornando-os inclusive, mais reais. A rigidez da forma flamenga parece se dissolver aqui em uma leveza que acompanha os movimentos dos personagens e do drapejamento de suas vestes. São figuras menos estanques se comparadas à Madona de Memling do painel central do Tríptico Portinari, presente hoje no Staatliche Museen, em Berlim, no qual o artista parecia estar mais preocupado em cumprir com a forma clássica equilibrada do que em atingir um sentimento religioso mais comovente. Neste aspecto, a pintura aqui analisada parece se aproximar mais das composições de Dürer, uma vez que este artista apresenta maior vivacidade e comoção emocional, como podemos ver em Madona da pêra, conservada no Kunshistorisches Museum. A composição cênica caracterizada pela ausência de paisagem e pelo fundo escuro que realça as qualidades formais dos personagens e a feição da Madona torna esta obra esteticamente parecida àquela atribuída a Mabuse. No entanto, há um outro fator que as aproxima mais efetivamente: a escolha no investimento de uma intimidade cênica entre Maria e o Menino, na pintura da FEK traduzida no jogo de panejamentos que os une quase como uma ligação umbilical, e na obra de Dürer revelada no olhar e nas mãos de Maria que acomodam o Menino em seu colo. Duas cenas pouco ornamentadas e com excesso de 
panejamentos que nos remetem a uma forma uterina do aconchego. Há, portanto, nesta Madona da FEK uma nítida ênfase na representação de seus personagens segundo uma eloqüência sentimental, característica que parece derivar mais da estética do Humanismo renascentista italiano do que propriamente dos flamengos.

Migliaccio observa no catálogo da Fundação Eva Klabin a forte relação entre a pintura do acervo carioca e outra conservada no Policka Museum, na República Checa. A posição corporal do Menino e a modelagem dos elementos cênicos que o envolvem, como a maneira que a Madona o segura e a forma que o seu véu cai sobre a bancada demonstram essa semelhança que também podem ser vistas em uma outra pintura, conservada no Museu de Belas Artes de Valenciennes, na França. Esta se aproxima ainda mais à do Policka: as feições de suas Madonas, os adornamentos das golas de seus vestidos e seus cabelos, além da presença da colunata grega na ambientação interna da cena e a localização da paisagem. Ambas as pinturas conservam o nome de Mabuse como autor. Poderíamos considerar estas informações como verdadeiras cogitando a possibilidade deste artista ter se dedicado ao aprimoramento desta representação, ou então ponderar sobre a probabilidade de uma delas se tratar de uma cópia de Mabuse. Comparando estas três obras às produções plásticas deste artista, a que mais se afasta de sua tendência pictórica é a do acervo nacional, devido principalmente à ausência de paisagem, um elemento tão fundamental nas suas composições e bastante difundido na tradição flamenga, mas ao mesmo tempo, uma característica pouco suficiente para que se possa negar tal autoria.

Mabuse, até o século XVII era considerado como um dos principais artistas que enriqueceram as tradições pictóricas flamengas através das influências italianas absorvidas principalmente ao longo de sua viagem a Roma em 1508, na comitiva de Felipe de Borgonha. Muitos autores, como Guicciardini, Vasari e Van Mander o classificavam como libertador da arte flamenga das correntes medievais, das formas rígidas típicas dos Países Baixos, difundindo uma maior plasticidade às figuras, baseando-se principalmente nas pesquisas pictóricas dos mestres renascentistas. Em contrapartida, os estudos recentes têm apontado uma nova perspectiva na análise destas influências italianas, buscando valorizar a arte flamenga da época. Gustav Glück em seu texto "Mabuse and the development of the Flemish Renaissance" percebe que logo após a sua volta a Flandres, as obras de Mabuse ainda eram mais caracteristicamente flamengas do que italianas. Inicialmente, demonstra maior interesse nas 
representações das ruínas romanas do que em Michelangelo e Rafael, até mesmo devido ao fato destes artistas nesta época ainda não terem estabelecido seus lugares de destaque. Já Max Friedländer não nega que Mabuse tenha sido afetado pelo espírito do Renascimento italiano, mas isso, no entanto, não teria mudado a sua forma. As influências do extremo sul europeu, portanto, teriam sido absorvidas por ele mais efetivamente através das versões germânicas de Dürer do que das originais. A partir destas novidades estéticas, trazidas diretamente pelos italianos ou pelos artistas nórdicos, a representação das figuras de Mabuse se torna mais arredondada e forte, se afastando daquela angularidade gótica. O corpo humano passa a ser o principal objetivo, reduzindo, portanto, a importância da paisagem na composição geral. E é neste contexto que devemos analisar Madona com Menino, o que justifica a datação apontada por Migliaccio, pois considera que a sua execução tenha ocorrido no período posterior à sua viagem quando as pesquisas plásticas de Florença se espalhavam pelo resto da Europa.

A composição intimista desta pintura se contrasta com a profundidade longínqua daquela atribuída a Tosini. A paisagem como aplicação da perspectiva linear clássica tanto ressaltada durante $\mathrm{O}$ Renascimento, sugere aqui uma ambientação mais extensa que apesar de abarcar os personagens da cena em primeiro plano, ainda se mostra vasta ao fundo. A pincelada precisa das figuras humanas que domina seus traços, movimentos corporais e drapejamentos parece se diluir na representação do caminho sinuoso que nos deixa a dúvida se representa um rio ou uma estrada, devido à idéia de velocidade sugerida pela rápida pincelada. Notamos também que o autor desta obra estava a par das pesquisas estéticas de Leonardo da Vinci, já que parece aplicar a sua técnica do sfumato na representação da paisagem, uma característica que pode aproximar esta pintura à autoria de Andrea del Sarto, uma vez que este trabalhou com Leonardo para a corte francesa.

Tratando das figuras humanas, percebemos a predominância da forma serpentinada do corpo que desafia as limitações naturais. A composição demonstra ter uma despreocupação com a proporcionalidade das figuras, evidenciada no grande tamanho do Menino, se comparado à Madona e nas mãos espalmadas da Virgem que parecem desproporcionais ao resto de seu corpo. Há um elemento que confirma esta brincadeira óptica: o pé à esquerda do quadro, que devido à sua posição parece pertencer ao Menino, apesar da diferença de tamanho deste para seu outro 
pé, ou então à Maria, o que a obrigaria estar em uma posição contorcida naturalmente impossível.

Estes esquemas visuais foram muito explorados no Quinhentos, uma tendência que segundo Anthony Blunt traduz uma maturidade dos artistas italianos que não estavam mais interessados em pesquisar a beleza da forma natural e sim em experimentar as técnicas já exploradas pelos grandes mestres. Um artista que neste aspecto se aproxima à pintura da FEK é Ângelo Bronzino. Em Vênus, Cupido e o Tempo, da National Gallery, de Londres, percebemos esta tendência à formação de um só organismo através do encaixe das figuras humanas. A multiplicidade clássica ressaltada por Wölfflin, que nos permite isolar os elementos da cena parece ser substituída por uma unidade, tornando praticamente impossível distinguir os limites corporais de seus personagens. Estas obras também se relacionam segundo o caráter paradoxal de suas composições que provocam sensações ambíguas: enquanto Bronzino faz a serenidade e placidez de Vênus e Cupido conviverem com a dramaticidade das máscaras teatrais e feições de horror ao fundo do quadro, na obra da FEK há uma concomitância entre a calma de Maria e seu filho e a paisagem sombria e fugidia ao fundo.

Anthony Blunt, em seu livro "Teoria artística na Itália", ao analisar os afrescos de Andrea del Sarto encontrados na Santíssima Annunziata, se refere a uma certa "acentuação iluminista", como uma relevante característica deste artista, uma técnica que cria a impressão de uma luminosidade vinda de fora da tela, produzindo em suas figuras um sombreamento. Podemos notar que a pintura do acervo carioca também apresenta esta técnica, evidenciada principalmente na sombra do Menino projetada no vestido da Virgem.

Esta pintura não consiste na única obra que aproxima os nomes destes artistas. Ambos Gertrude Coor-Achenbach em seu texto "Two early Madonnas by Michele Tosin?" compara uma Madona de Tosini, conservada em coleção particular em Nova Iorque com outra de mesmo tema de Andrea del Sarto da Galeria Borghese. A autora afirma que a primeira fase da carreira de Tosini foi afetada pelas influências de Andrea del Sarto, enquanto na segunda fase os nomes de Michelangelo, Vasari e Salviati receberam maior destaque. Segundo a datação estimada por Migliaccio, o quadro conservado na FEK seria desta segunda fase, considerando, portanto, que esta pintura pertenceria a um período de maior maturidade do artista, aproximando a sua técnica a uma nova forma explorada por artistas mais tarde conhecidos como "maneiristas". Não se pretende aqui, 
no entanto, entender o Maneirismo como um estilo uniforme, mas sim abordá-lo como uma tendência artística de reação política e religiosa da aliança entre a Espanha e o papado de 1530, que culminaria na crise do Renascimento devido à essência anti-humanista da Reforma. Esta reação se manifestou tanto na Itália quanto nos Paises Baixos, com os Maneiristas da Antuérpia, do qual Mabuse fazia parte, sendo uma das características deste grupo a secularização vigorosa de temas sacros.

Segundo Anthony Blunt, o Maneirismo separou pela primeira vez a arte da natureza, preocupando-se mais com a própria arte, com seus modos e processos do que com o valor e com o significado das coisas representadas:

"Esse apelo final ao olho é típico da pintura maneirista florentina e da óptica de Vasari. Para o grupo de artistas que ele representa, a pintura deixou de ser a busca intelectual intensamente séria que havia sido para os artistas do Alto Renascimento. Tornou-se antes um jogo de habilidade, apelando para um amor ao engenho e deixando imperturbadas as faculdades racionais" ${ }^{1}$.

Portanto, a beleza como qualidade racional alcançada através de regras técnicas, muito difundida nos escritos de Alberti, cede lugar à graça, como qualidade indefinível que depende do juízo, logo do olho, pretendida e admirada por Vasari.

Apesar destas relações apontadas entre a pintura da FEK e a forma maneirista e às produções de Bronzino e Vasari, com quem trabalhou na decoração do Palazzo Vecchio, percebemos que os esquemas visuais de Michele Tosini são menos rebuscados que aqueles explorados pelos artistas supracitados, sendo, portanto, mais de acordo com as exigências das normas da Contra-Reforma. Analisando uma obra de mesmo tema de Tosini, conservada no Palmer Museum of Art, notamos uma maior contenção ao desequilíbrio da forma clássica. Suas figuras ainda tendem a frontalidade e organização equilibrada dos personagens. Podemos relacionar, portanto, a Madona da FEK às exigências contra-reformistas presentes na Teoria do Decoro, que objetivava, entre outras coisas, incitar a piedade e fortalecer o sentimento religioso. Segundo esta teoria:

“(...) as figuras devem estar vestidas de maneira adequada à sua posição e caráter, seus gestos devem ser apropriados, o cenário deve ser escolhido corretamente e o artista deve sempre considerar se está

1 BLUNT, Anthony. Teoria artística na Itália: 1450 - 1600. São Paulo: Cosac \& Naify Edições, 2001, p. 127. 
executando uma obra para uma igreja ou um palácio, para um aposento oficial ou um gabinete particular" 2.

De acordo com estas determinações percebemos o apelo mais fantástico que representa Maria mais como uma visão mística, uma aparição, do que de acordo com aquele contexto intimista e sentimental evidenciado na pintura holandesa atribuída a Mabuse.

Era necessário, segundo as regras do Concílio, demonstrar nos personagens retratados seus atributos e vestimentas próprios, procurando tornar suas alegorias simples e inteligíveis. Os temas deveriam se restringir à história da bíblia da maneira mais clara, sem torná-la, no entanto, mais atraente do que o devido, uma estética que se afastava daquela pretendida pelos ditos maneiristas, que priorizavam a graça em detrimento da beleza clássica, interferindo na composição da natureza retratada.

Em Madona com Menino e São João Batista os atributos são muito mais evidentes e numerosos do que em Madona com Menino, demonstrando uma maior preocupação em esclarecer a identidade dos personagens representados. A composição da primeira não nega sua sacralidade corroborada no gesto de adoração de Maria, na presença do atributo de São João Batista, a cruz de bambu, e no globo terrestre no qual o Menino se apóia, representando seu controle divino do mundo.

Já a pintura atribuída a Mabuse parece se preocupar mais em destacar o aspecto sentimental da cena do que em cuidar de seu caráter religioso, o que nos permite inclusive ponderar sobre a possibilidade da mesma representar uma cena de interior entre mãe e filho e não propriamente a Virgem com o Menino Jesus, uma possibilidade interpretativa que seria extremamente condenada pela Contra-Reforma. Em contrapartida, a força expressiva desta pintura se concentra na relação entre Maria e seu filho, reforçada pela presença do véu que desce da cabeça da Virgem e com o qual o Menino brinca. Podemos estabelecer uma analogia deste véu com aquele entregue ao jovem judeu quando atinge a sua puberdade (Bar Mitzva), simbolizando o seu ingresso no mundo religioso, e que também o envolve em sua morte. Uma leitura reforçada pela presença das pequenas cerejas caídas aos pés do Menino, que segundo Migliaccio aludiriam a gotas de sangue vivo.

2 BLUNT, Anthony. Teoria artística na Itália: 1450 - 1600. São Paulo: Cosac \& Naify Edições, 2001, p. 163. 
Concluindo esta análise, podemos dizer que apesar destas diferentes estéticas compositivas aqui ressaltadas, as pinturas em questão se aproximam no que tange ao objetivo da comoção afetiva da imagem da Virgem como reforço da crença religiosa.

\section{Bibliografia}

ARGAN, Giulio Carlo. História da Arte Italiana. Volumes II e III. Tradução de Wilma De Katinszky. São Paulo: Cosac \& Naify, 2003.

BLUNT, Anthony. Teoria artística na Itália: 1450 - 1600. São Paulo: Cosac \& Naify Edições, 2001.

CAMPBELL, Lorne. Renaissance Portraits. New Heaven e Londres, Yale University Press, 1990.

COOR-ACHENBACH, Gertrude. Two early Madonnas by Michele Tosini. In: The Art Quarterly. Detroit: Metropolitan Museum of Art; Founders Society Detroit Institute of Arts, 1938.

DICKENS, A. G. A Reforma e a Europa do século XVI. Lisboa: Editorial Verbo, 1971.

GLUCK, Gustav. "Mabuse and the development of the Flemish Renaissance". In: The Art Quarterly. Detroit: Metropolitan Museum of Art; Founders Society Detroit Institute of Arts, 1938. 


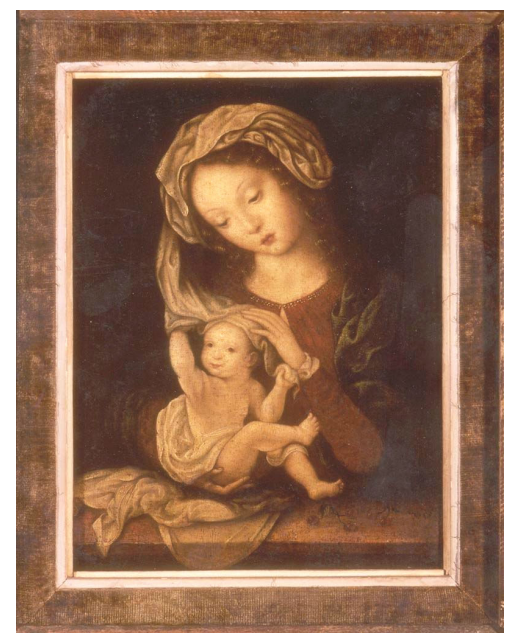

Madona com Menino e cerejas

Jan Gossaert - Mabuse

1520

Óleo sobre tela

$31 \times 22,8 \mathrm{~cm}$

Fundação Eva Klabin; Rio de Janeiro

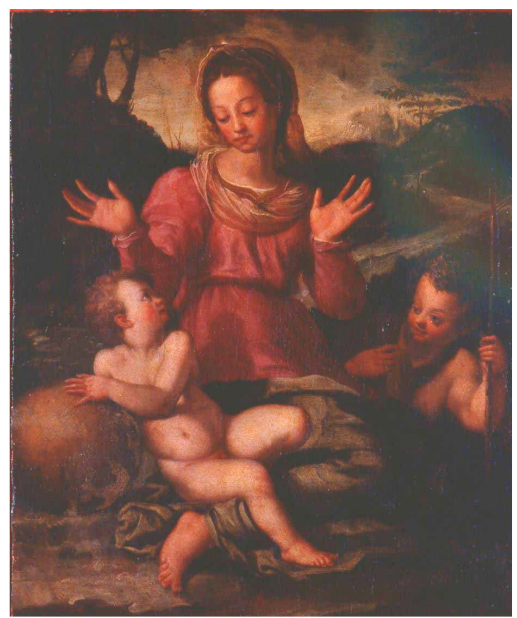

Madona com Menino e São João Batista

Michele di Rodolfo del Ghirlandaio - Michele Tosini

1570

Óleo sobre madeira

$50,5 \times 41,5 \mathrm{~cm}$

Fundação Eva Klabin; Rio de Janeiro 